\title{
Postabortion family planning benefits clients and providers
}

James R. Foreit

Population Council

Follow this and additional works at: https://knowledgecommons.popcouncil.org/departments_sbsr-rh How does access to this work benefit you? Let us know!

\section{Recommended Citation}

Foreit, James R. 2005. "Postabortion family planning benefits clients and providers," FRONTIERS Program Brief. Washington, DC: Population Council. 


\section{Postabortion Family Planning Benefits Clients and Providers}

A woman's fertility can return quickly following an abortion or miscarriage, from as early as two weeks (Bongaarts and Potter 1983). Yet recent data show high levels of unmet need for family planning among women who have been treated for incomplete abortion. This leaves many women at risk of another unintended pregnancy and in some cases, subsequent repeated abortions and abortion-related complications (Savelieva et al. 2002). It is thus vital for programs to provide a comprehensive package of postabortion care (PAC) services that includes medical treatment, family planning counseling and services, and other reproductive health services such as STI evaluation and treatment, HIV

\section{Provision of family} planning methods is a central feature of postabortion care. Ensuring reliable on-site availability of family planning methods for all clients following abortion or miscarriage can result in benefits for clients, providers, and programs. counseling and/or testing, and community support and mobilization.

\section{Providing family planning services within PAC benefits clients and programs}

Facilities that can effectively treat women with incomplete abortions can also provide contraceptive services, including counseling and appropriate methods. Appropriate pre-discharge contraception can be provided in conjunction with all emergency procedures including inpatient and outpatient dilation and curettage (D\&C), manual or electric vacuum aspiration (MVA or EVA). Any provider who can treat incomplete abortion can also provide selected family planning methods.

Clients, providers, and programs benefit when family planning methods are provided to postabortion clients at the time of treatment:

\section{Higher contraceptive}

acceptance. An operations research (OR) study of postabortion clients in Kenya found that 75 percent accepted family planning methods when they were provided on the ward, while only 41 percent obtained a method when asked to visit a separate site within the same hospital after discharge (Solo et al. 1999). An OR study in Russia showed

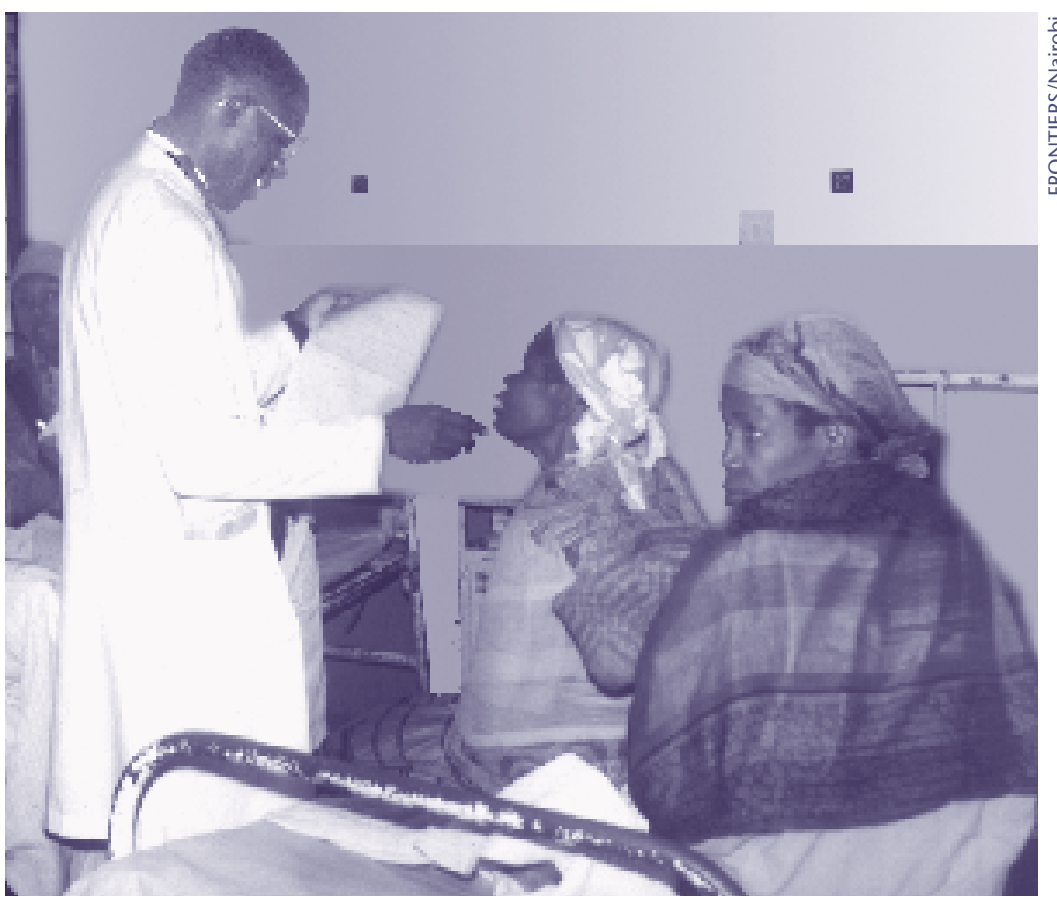

Women in the obstetric ward, Meru District Hospital, Kenya. 
that the introduction of postabortion family planning service delivery, involving training in counseling skills and job aids for providers, led to increased use of modern contraceptive methods at 12 months postabortion (Savelieva et al. 2002).

\section{Increased access to family planning information and informed method choice.}

Following an intervention to strengthen family planning as part of PAC services in rural health districts in Senegal, nearly twice as many PAC clients reported receiving family planning counseling after the intervention than at baseline (70\% versus $38 \%)$. In addition, 20 percent of PAC clients left the facility with a modern contraceptive method versus none at baseline, as these clients had received only referrals (EngenderHealth 2003).

When providers at five Honduran hospitals were trained to provide family planning counseling and methods to postabortion clients, the proportion of women receiving a method increased almost four-fold, and the number of women who left without a method dropped by half (see Figure).

\section{Improved long-term outcomes.}

A health facility in Brazil reduced pregnancy-related re-hospitalizations by 60 percent within 21 months after offering pre-discharge IUDs.

\section{Components of PAC}

1. Emergency treatment

2. Family planning counseling and service delivery, STI evaluation and treatment, HIV counseling and/or referral for HIV testing

3. Community empowerment through community awareness and mobilization

Source: USAID Postabortion Care Model 2004.

\section{Figure 1. Provision of Postabortion Family Planning in Hospitals, Honduras}

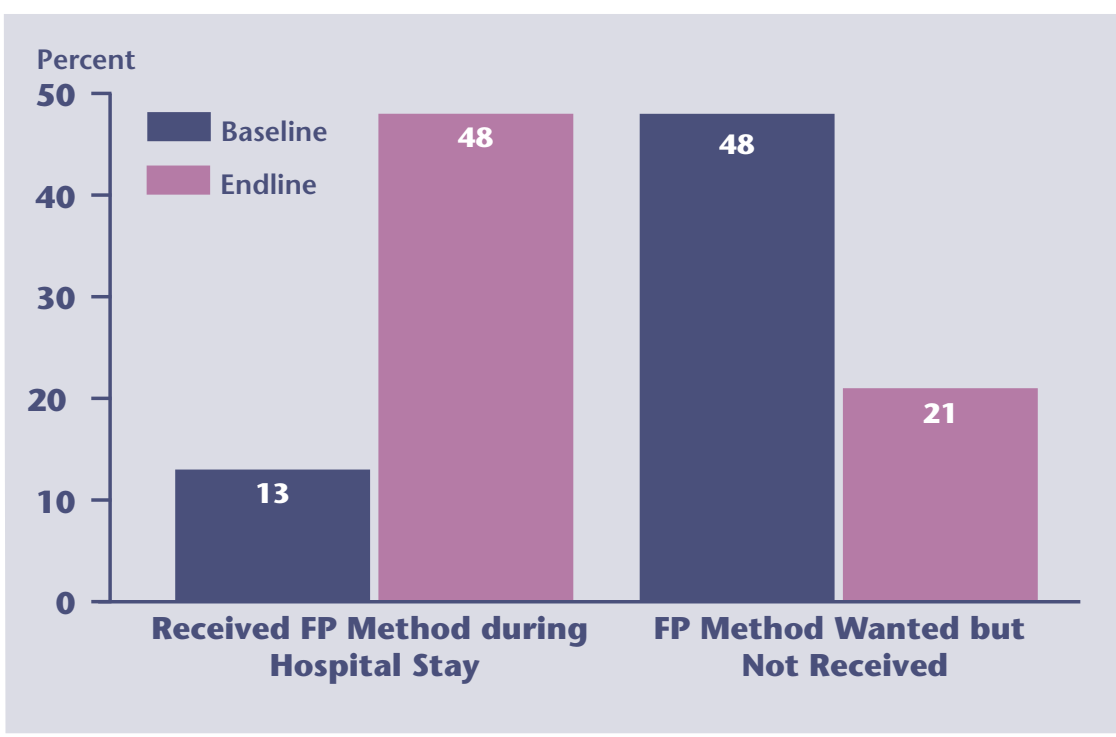

Source: Medina et al. 2001.

Cost savings to programs. The Brazilian facility avoided two outpatient visits and saved $\$ 2.80$ for every $\$ 1.00$ invested in postpartum and postabortion contraception (Population Council 1993).

Cost savings to clients. Women save the time, money, and risks of unintended pregnancy when provided with complete postabortion services before discharge.
Reduced abortions. An operations research study in Perm, Russia found that 50 to 60 percent of postabortion clients were not using contraceptives one year after the procedure. Over 10 percent had repeat abortions within 12 months. While the intervention package did not lead to an overall reduction in repeat abortion, receiving family planning counseling at the follow-up visit was an important factor in reducing repeat abortion for individuals (Savelieva et al. 2002). 
The Population Council is an international, nonprofit, nongovernmental institution that seeks to improve the wellbeing and reproductive health of current and future generations around the world and to help achieve a humane, equitable, and sustainable balance between people and resources. The Council conducts biomedical, social science, and public health research and helps build research capacities in developing countries. Established in 1952, the Council is governed by an international board of trustees. Its New York headquarters supports a global network of regional and country offices.

The Frontiers in Reproductive Health Program (FRONTIERS) applies systematic research techniques to improve delivery of family planning and reproductive health services and influence related policies. FRONTIERS is funded by USAID and led by the Population Council in collaboration with Family Health International.

Frontiers in Reproductive Health Program (FRONTIERS) Population Council 4301 Connecticut Avenue, NW, Suite 280

Washington, DC 20008

Telephone: (202) 237-9400

Facsimile: (202) 237-8410

E-mail: frontiers@pcdc.org www.popcouncil.org/frontiers

\section{Frontiers in Reproductive Health Program Brief No. 4}

Author: James R. Foreit

Editors: Stephanie Joyce, Laura Raney

Design: Vincent Hughes Visualization The assistance of the following reviewers is appreciated: Carolyn Curtis, Emma Ottolenghi, Patricia Stephenson, and John Townsend.

This publication was made possible through support provided by the U.S. Agency for International Development (USAID) under the terms of Cooperative Agreement No. HRN-A-00-98-00012.

The opinions expressed herein do not necessarily reflect the views of USAID.

Suggested citation: Foreit, James R. 2005. "Postabortion Family Planning Benefits Clients and Providers," FRONTIERS Program Brief No. 4. Washington, DC: Population Council.

C 2005 the Population Council, Inc.

This publication may be reproduced in whole or in part without permission of Population Council provided full source citation is given and the reproduction is not for commercial purposes.

ISSN 1546-6612 